\title{
ANÁLISE DAS PRÁTICAS EMPRESARIAIS DE SUSTENTABILIDADE NAS EMPRESAS DE CONSTRUÇÃO PESADA DO SETOR DE INFRAESTRUTURA NO BRASIL
}

\section{RESUMO}

Osvaldo Luiz Gonçalvez Quelhas2

Sergio Luiz Braga França3

O presente estudo realiza confrontação entre os referenciais teóricos considerados para o desenvolvimento sustentável e a sua incorporação nas práticas e modelos de decisão utilizados nas empresas de construção pesada. Trata-se de um estudo realizado a partir de análise documental e em relatórios de sustentabilidade divulgados pelas empresas. Utiliza-se de recurso metodológico da análise de conteúdo para desenvolver prescriçóes sobre a sustentabilidade na gestão das empresas analisadas. Os resultados apontam quatro principais conclusóes: 1) o contexto social, político e econômico direcionou as empresas para a implantação de práticas de gestáo sustentáveis; 2) o desenvolvimento de pessoas segue o modelo tradicional de treinamento e desenvolvimento; 3) observam-se evidências do esforço em equilibrar objetivos econômicos, obtenção de lucro, com práticas de responsabilidade social como forma de caracterizar o compromisso empresarial com a sustentabilidade e 4) nas práticas empresariais analisadas não se adotam medidas eficazes e indispensáveis para transformar os modelos de decisão, que continuam a priorizar o fator econômico em detrimento das vertentes social e ambiental.

Palavras-chave: Responsabilidade Social Empresarial, Desenvolvimento Sustentável, Construção Pesada.

\section{ABSTRACT}

This study conducts the confrontation between the theoretical frameworks considered for sustainable development and its incorporation in practices and decision models used in heavy construction companies. This is a study from document analysis and sustainability reports published by companies. Was used the methodological's content analysis to identify requirements on sustainability in the management of the companies analyzed. The results point to four main conclusions: 1) the social, economic and political context directed the companies to implement sustainable management practices; 2) the development of people follow the traditional model of training and development; 3) evidence has been seen of the effort to balance economic goals and the profit with social responsibility practices as a way to characterize the corporate commitment to sustainability; 4) in the business' practices analyzed are not adopted effective measures and necessary to transform the decision models, which continue to prioritize economic factor in the expense of social and environmental.

Key words: Corporate Social Responsibility, Sustainable Development, Heavy Construction

1 luisarruda@oi.com.br

2 quelhas@latec.uff.br

3 sfranca@latec.uff.br 


\section{INTRODUÇÃO}

Empresas do setor da construção pesada executam obras de construção de estradas, portos, pontes, aeroportos, hidroelétricas, túneis, dentre outras.

Em 2007, o governo brasileiro lançou o Programa de Aceleração do Crescimento - PAC - com a convicção de que os investimentos públicos são indutores do crescimento econômico. As obras de infraestrutura formam a base deste programa de crescimento econômico, criando assim um mecanismo estratégico para o desenvolvimento nacional no sentido da integração e redução das desigualdades regionais e sociais. $\mathrm{O}$ impacto social e ambiental das obras de grande porte é relevante e induz a consequências de perdas econômicas

Diante desse movimento de expansão, o setor de construção pesada, responsável pelas obras de infraestrutura, vem introduzindo modelos de gestâo para reduzir o risco social, o risco ambiental e, consequentemente, o econômico, baseados na sustentabilidade como inspiração para realizar empreendimentos com impactos sociais positivos, respeito ao meio ambiente e economicamente viáveis.

Neste sentido, Afonso (2006) dá relevante contribuição para a Gestão, na medida em que questiona o uso da noção de sustentabilidade no âmbito empresarial. Segundo a autora, grande número de empresas tem incorporado o conceito de sustentabilidade a seu discurso sem, entretanto, alterar seus processos de decisóes e de produção.

O objetivo deste estudo trata da confrontação entre os referenciais teóricos considerados como paradigmas da sustentabilidade empresarial e a sua incorporaçáo nas práticas e modelos de decisão utilizados nas empresas de construção pesada.

Este artigo analisa a sinergia entre os referenciais teóricos de sustentabilidade empresarial e as práticas identificadas em empresas de construção pesada, brasileiras, de atuação internacional.

\section{SUSTENTABILIDADE: DISCURSOS E PRÁTICAS}

A revisão da literatura sobre desenvolvimento sustentável e sustentabilidade indica a diversidade de abordagens que estão incorporadas nos sistemas de gestão das empresas (Sachs, 1986; Chesnais, 1996; Layrargues, 1997; Lima, 2003; Deluiz e Novicki, 2004).
No mundo, grandes empresas foram motivadas a implantar políticas de desenvolvimento sustentável, entre os anos de 1970 e 1980, pressionadas pelo contexto político, pelos movimentos sociais de defesa do meio ambiente e pelas alteraçóes no ambiente competitivo, decorrente da globalização econômica. No caso das empresas brasileiras esse movimento é mais recente e remonta aos anos de 1990 e 2000 (Arruda e Quelhas, 2010).

Outro importante ponto encontrado nas literaturas relacionadas ao tema foi a identificação de duas matrizes conceituais que polarizam os debates sobre o desenvolvimento sustentável e a sustentabilidade. A primeira, sobre desenvolvimento sustentável, corresponde ao "Relatório Nosso Futuro Comum" (Wced, 1987) e detém a hegemonia sobre o tema. Seu discurso promete elevar a produção com a redução do consumo de recursos naturais e diminuição de lançamento de resíduos no meio ambiente. A segunda, relacionada à sustentabilidade, tem origem nas propostas do eco-desenvolvimento (Sachs, 2007). Ela se coloca contrária ao discurso da primeira por considerar importante o papel da sociedade civil na transição para a sustentabilidade, na priorizaçáo da equidade social e na desconfiança da capacidade do mercado como alocador de recursos (Layrargues, 1997; Deluiz e Novicki, 2004).

Um dos modelos que abordam os motivadores da sustentabilidade organizacional é o de Munilla \& Miles (2005), que indica que a Sustentabilidade Empresarial desenvolve-se a partir de um dos seguintes motivos:

- Estratégicos, visando a criação de vantagem competitiva (Miles e Covin, 2000);

- Por mera complacência, ou seja, precisa ser implementada, já que é exigida pelo marco legal que rege a organização (Miles \& Covin, 2000);

- Devido a pressóes de diferentes grupos sociais ou partes interessadas (Miles, Munilla e Covin, 2002).

Para Porter e Kramer (2006), as empresas que respondem ao chamado da sustentabilidade podem fazê-lo adotando uma abordagem responsiva ou estratégica. O que define uma e outra abordagem é justamente o envolvimento ético da empresa com as questôes da sociedade.

Uma empresa responsiva procura ter alguma atuação comunitária e reduzir os danos sociais 
e ambientais causados pelas atividades de sua cadeia de valor. Na prática, significa que ela reage ao que a sociedade the cobra, minimizando, de um lado, os seus riscos socioambientais e, de outro, fazendo investimentos em causas mais genéricas, de evidente interesse social, mas que não interferem diretamente nas suas operaçôes nem influenciam sua competitividade no médio e no longo prazo.

Já na sustentabilidade estratégica, a empresa transforma as atividades de sua cadeia produtiva para, ao mesmo tempo, beneficiar a sociedade e reforçar sua estratégia de negócio. Ao realizar o seu investimento social, ela seleciona temas que, de alguma forma, contribuem para melhorar a competitividade do seu empreendimento. Em ambas as classificaçóes (responsivas e estratégicas), Porter e Kramer (2006) mostram que quanto maior a relação das temáticas social e ambiental com a atividade de negócio da empresa, maiores poderão ser suas oportunidades de sucesso na competitividade e na eficácia nos benefícios sociais e ambientais.

Para Cheibub e Locke (2002) uma empresa socialmente responsável é resultado de um empreendimento coletivo e caracteriza-se pelo cumprimento das regras do jogo democrático, não buscando obter vantagens indevidas ou especiais. É uma empresa engajada com as ações que reforçam a democracia pelo fortalecimento da esfera pública de decisão social.

\section{METODO DE PESQUISA}

O estudo está baseado na revisão da literatura e na análise de documentos das empresas estudadas. Para isso analisa as açôes de sustentabilidade descritas nos Relatórios de Sustentabilidade de três empresas brasileiras que atuam no setor da construção pesada.

Utilizou-se a técnica da Análise Documental para selecionar nos relatórios os aspectos relacionados aos modelos de negócios, aos conceitos e práticas da sustentabilidade, além de açôes de educação corporativa. A partir da análise de conteúdo dos documentos e da produçáo científica identificada buscou-se desenvolver análise crítica quanto a incorporaçáo dos conceitos do desenvolvimento sustentável nas práticas e modelos de decisão utilizados nas empresas de construção pesada.

\section{CARACTERIZAÇÃO DAS EMPRESAS ESTUDADAS}

O setor de construção pesada no Brasil teve nos anos de 2008 e 2009 uma trajetória de crescimento impulsionado pela aceleração das obras de infraestrutura, tanto do governo federal como dos governos estaduais. O faturamento das 100 maiores construtoras em 2009, de acordo com a revista $O$ Empreiteiro, edição de julho de 2010, foi o maior realizado no período de 15 anos e apresenta crescimento pelo quinto ano consecutivo.

O critério de seleção das três empresas para este estudo foi "Empresas com maiores faturamentos no ano de 2009" tendo como fonte o ranking publicado na revista "O Empreiteiro", edição Jul/2010. As três empresas analisadas atuam nacionalmente e têm relevante papel em construção pesada. As conclusóes obtidas pela análise de suas açóes em sustentabilidade adquirem, portanto, possibilidade de comparação com outras empresas da indústria da construção pesada.

Os relatórios de sustentabilidade dessas empresas, assim como o ranking com as empresas de maior faturamento estáo disponíveis ao publico na internet. Todavia, foi assegurada a confidencialidade das mesmas passando a nomeá-las como empresa $\mathrm{A}$, empresa $\mathrm{B}$ e empresa $\mathrm{C}$, pois não houve autorizaçáo dessas empresas para citar seus nomes.

O Quadro 1 apresenta a caracterização das empresas objeto dessa pesquisa.

Quadro : Caracterização das empresas

\begin{tabular}{|c|c|c|c|}
\hline \multirow{2}{*}{ Categorias } & \multicolumn{3}{|c|}{ Empresas } \\
\cline { 2 - 4 } & A & B & C \\
\hline $\begin{array}{c}\text { Receita bruta da } \\
\text { holding (bilhóes) }\end{array}$ & $\mathrm{R} \$ 40,6$ & $\mathrm{R} \$ 19,0$ & $\mathrm{R} \$ 18,2$ \\
\hline $\begin{array}{c}\text { Receita bruta no } \\
\text { setor de engenharia } \\
\text { (em bilhóes) }\end{array}$ & $\mathrm{R} \$ 18.7$ & $\mathrm{R} \$ 6,1$ & $\mathrm{R} \$ 6,0$ \\
\hline $\begin{array}{c}\text { Número de } \\
\text { empregados próprios }\end{array}$ & 87.662 & 47.297 & 18.293 \\
\hline
\end{tabular}

FONTE: Relatório de Sustentabilidade de 2009 das empresas 


\section{ITENS DA PESQUISA}

Nos relatórios de sustentabilidade publicados por estas empresas foram analisadas as dimensóes e categorias indicadas no quadro 2 , que são constituintes do modelo de "Relatório de Sustentabilidade" proposto pelo GRI - Global Reporting Initiative (2012).

\section{DELIMITAÇÃO TEMPORAL E GEOGRÁFICA DA PESQUISA}

O levantamento dos dados da pesquisa concentrou-se em empresas brasileiras do setor de construção pesada. Utilizaram-se os relatórios de sustentabilidade do ano de 2009 disponibilizados nos sites corporativos das empresas analisadas (GRI, 2012).

\section{RESULTADOS}

Nesta seção são apresentados os resultados da análise documental. As anotaçóes dos pesquisadores foram organizadas em dimensóes e categorias (Quadro 2) à procura de padróes, regularidades, oposições e contradiçôes que permitissem uma análise acurada dos dados.

\section{MODELOS DE NEGÓCIO}

Segundo Braconi (2010) a transparência e a clareza de papéis e responsabilidades são princípios que fundamentam a governança corporativa. Tais aspectos devem nortear a atuação das organizaçôes empresariais no processo de crescimento e de geração de valor para os acionistas e as demais partes interessadas. Além do modelo de governança corporativa, a estrutura executiva corporativa bem definida é um importante aspecto para gestão de riscos e implementação das estratégias empresariais.

O Quadro 3 apresenta a síntese de práticas de governança empresarial identificadas nos relatórios das três empresas estudadas, obtidos na etapa de análise documental.

Quadro : Dimensóes e categorias da análise documental

\begin{tabular}{|c|c|c|}
\hline Dimensão & Categoria & Autores e Referencias \\
\hline $\begin{array}{l}\text { Conceitos de } \\
\text { Gestẫo }\end{array}$ & $\begin{array}{l}\text { Características do ambiente } \\
\text { político, social e } \\
\text { concorrencial no contexto } \\
\text { histórico da sustentabilidade } \\
\text { Tendências político- } \\
\text { filosóficas; Debate sobre } \\
\text { Desenvolvimento } \\
\text { Sustentável e } \\
\text { Sustentabilidade }\end{array}$ & 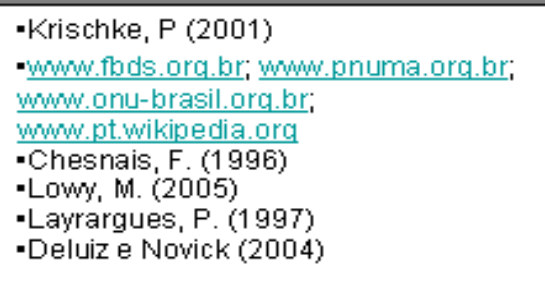 \\
\hline $\begin{array}{l}\text { Modelos de } \\
\text { negócio }\end{array}$ & $\begin{array}{l}\text { Os modelos econômicos e } \\
\text { impactos ambientais; } A \\
\text { abordagem da } \\
\text { sustentabilidade. } \\
\text { Certificação Internacional; } \\
\text { Indicadores de gestấo; } \\
\text { Práticas socioambientais }\end{array}$ & $\begin{array}{l}\text { - Quelhas, O. (2009) } \\
\text { - Relatórios de sustentabilidade } \\
\text { publicados pelas empresas estudadas } \\
\text { - Milkovich, G.T. (2000) } \\
\text { - Siche, R (2007) } \\
\text { - Calia, C. (2007) }\end{array}$ \\
\hline Pessoas & $\begin{array}{l}\text { Economia do conhecimento; } \\
\text { Capital intelectual. } \\
\text { Aprendizagem de ordem } \\
\text { inferior e superior; } \\
\text { Desenvolvimento de } \\
\text { competências }\end{array}$ & $\begin{array}{l}\text {-Dupas, G. (2008) } \\
\text {-Deluiz, N. (1996) } \\
\text {-Valle, R. (2003) } \\
\text {-Antunes, M.T (2002) } \\
\text {-Meister, J.C. (1999) } \\
\text {-Garrido, P. (2006) } \\
\text {-Teixeira, E (2005) }\end{array}$ \\
\hline
\end{tabular}


Quadro 3: Práticas de Governança Empresarial

\begin{tabular}{|c|c|}
\hline $\begin{array}{c}\text { Sujeitos da } \\
\text { pesquisa }\end{array}$ & Práticas Empresariais \\
\hline EMPRESA A & - Existência de Conselho de Administração \\
\hline EMPRESA B & $\begin{array}{l}\text { - Conselho de Administraçáo: composto pelo presidente e três vice-presiden- } \\
\text { tes. } \\
\text { - Foco na gestão das Divisōes de Negócios e tem assessoria de quatro comitês: } \\
\text { Corporativo, RH, Executivo e Financeiro de auditoria } \\
\text { - Há um Comitê de Sustentabilidade composto pelos mesmos integrantes } \\
\text { do Comitê Executivo do Grupo para deliberar sobre estratégias, metas e } \\
\text { indicadores de avaliaçấo }\end{array}$ \\
\hline EMPRESA C & $\begin{array}{l}\text { - O Conselho de Administração é composto por três representantes de cada } \\
\text { empresa sócia } \\
\text { - Todos os acionistas têm posição no Conselho. Nenhum membro do Conse- } \\
\text { lho de Administraçáo desempenha funçốes executivas }\end{array}$ \\
\hline
\end{tabular}

As estruturas de governança nas três empresas não se assemelham. A existência de um Conselho de Administração parece ser item comum. Destaca-se na EMPRESA B a constituição de um Comitê de Sustentabilidade como forma de manter a harmonia das estratégias e identidade das açóes em todas as empresas controladas. Esse Comitê exerce papel mobilizador, educador e disseminador das práticas de sustentabilidade para todas as empresas, de forma a assegurar que todos incorporem indicadores e metas sociais e ambientais na condução cotidiana da empresa.

\section{DIMENSÃO MATRIZES CONCEITUAIS}

A abordagem de negócio através da qual se cria valor de longo prazo para os acionistas e demais partes interessadas pressupóe debates sobre conceitos acerca do desenvolvimento sustentável e da sustentabilidade.

O Quadro 4 apresenta os destaques em relação à política de sustentabilidade encontradas nos relatórios das empresas pesquisadas. 
Quadro 4: Política de Sustentabilidade: resultado da análise do conteúdo dos Relatórios Empresariais de Sustentabilidade, publicados pelas empresas estudadas.

\begin{tabular}{|c|c|}
\hline Sujeitos da pesquisa & Práticas Empresariais \\
\hline EMPRESA A & $\begin{array}{l}\text { - A empresa declara que desenvolvimento sustentável faz parte de sua gênese e está presente nas } \\
\text { açóes daqueles que integram a organizaçáo. A liderança entende que suas açóes contribuem: } \\
\text { - com desenvolvimento econômico, pois gera resultados para clientes, acionistas e comunidades } \\
\text { onde atuam } \\
\text { - com o desenvolvimento social, pois cria oportunidades de trabalho e renda para a população } \\
\text { - com a preservaçáo ambiental, pois fazem uso racional dos recursos naturais utilizando-se de } \\
\text { tecnologias limpas, buscam a redução de resíduos e da mitigação dos impactos causados pelas } \\
\text { operaçôes. } \\
\text { - com a diversidade cultural, pois incentivam na organizaçáo a integraçáo de pessoas de diversas } \\
\text { origens, etnias, orientaçáo sexual e religiosa e respeitando usos e costumes. } \\
\text { - com a participaçáo política, pois contribuem ativamente na formulaçáo de Políticas Públicas que } \\
\text { visem promover o desenvolvimento sustentável } \\
\text { - Integra o grupo de empresas brasileiras signatárias do compromisso 'Carta Aberta ao Brasil' pelo } \\
\text { qual se compromete a realizar o inventário de suas emissóes e a implantar procedimentos que } \\
\text { levem à reduçáo das emissóes dos gases de efeito estufa }\end{array}$ \\
\hline EMPRESA B & $\begin{array}{l}\text { - Integra o grupo de empresas brasileiras signatárias do compromisso 'Carta Aberta ao Brasil' pelo } \\
\text { qual se compromete a realizar o inventário de suas emissóes e a implantar procedimentos que } \\
\text { levem à reduçáo das emissóes dos gases de efeito estufa. } \\
\text { - Trabalha internamente com uma 'Agenda Climática' onde sáo elencados compromissos para } \\
\text { orientar sobre a redução e mitigação das emissóes de Gases de Efeito Estufa (GEEs). } \\
\text { - Avalia o estágio de incorporaçâo das dimensóes da sustentabilidade por meio da metodologia } \\
\text { que desenvolveu denominada 'Radar da Sustentabilidade'. O Radar resulta de um questionário } \\
\text { baseado em indicadores do Índice de Sustentabilidade Empresarial (ISE), do Instituto Ethos e } \\
\text { do Guia Exame de Sustentabilidade. } \\
\text { - Assume como temas prioritários no processo de sustentabilidade: segurança no trabalho; pro- } \\
\text { gramas para fornecedores e clientes; educaçáo continuada em sustentabilidade para o público } \\
\text { interno; e inclusão de pessoas com deficiência e de aprendizes. } \\
\text { - Elenca e quantifica os riscos estabelecendo os sistemas de prevenção, avaliando os meios de } \\
\text { mitigá-los e estabelecendo os planos de contingências, seja para impactos ambientais, sociais, } \\
\text { econômicos ou inerentes ao desenvolvimento das obras. } \\
\text { - Realiza o programa de Parcerias para a Sustentabilidade como forma de capacitar os fornecedores } \\
\text { da área de energia para atender às exigências socioambientais estabelecidas pela empresa }\end{array}$ \\
\hline EMPRESA C & 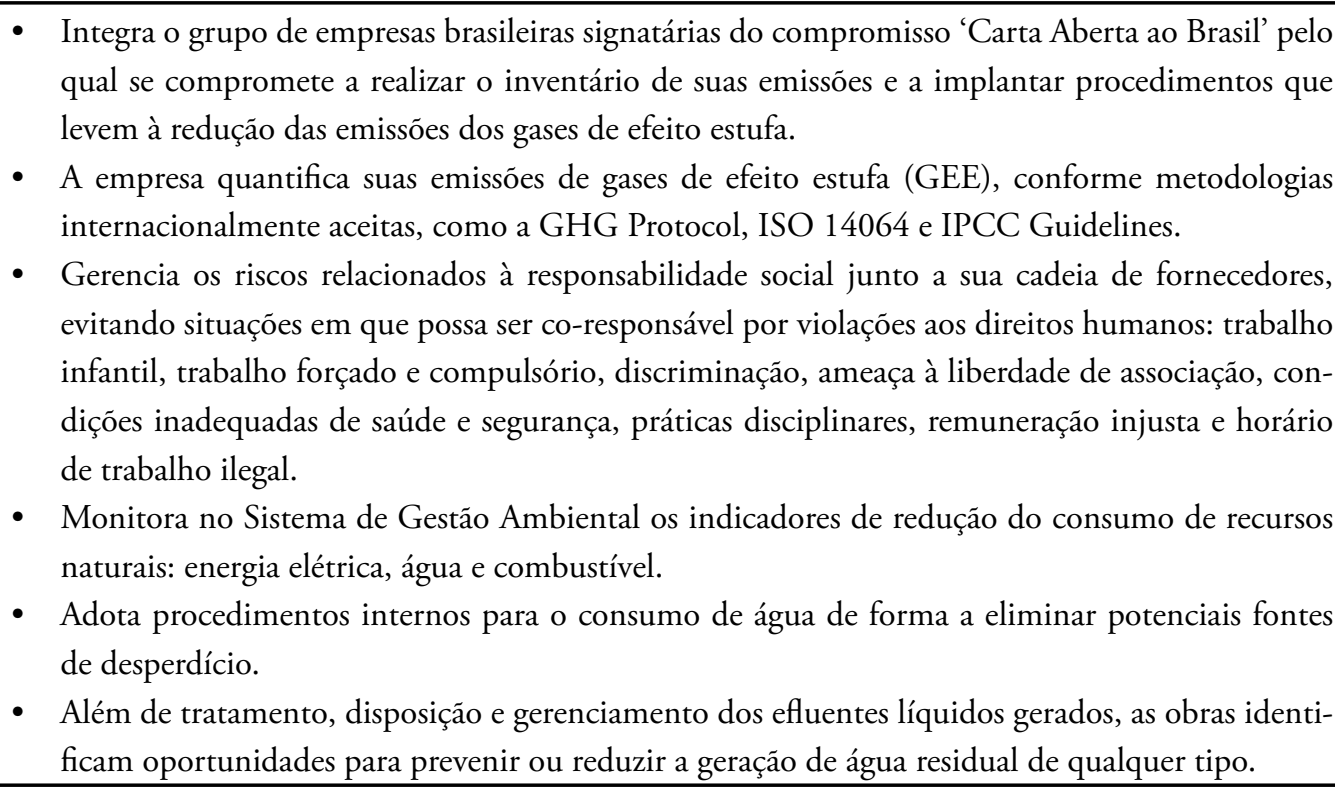 \\
\hline
\end{tabular}


Ao incorporar a abordagem da sustentabilidade, uma empresa reafirma o compromisso com uma estratégia de desenvolvimento sustentável e assume um desafio que vai além de suas operaçóes, posicionando-se como um agente transformador diante dos novos padróes de negócios e alavancagem do desenvolvimento social, ambiental e econômico de forma equilibrada e de longo prazo. As três empresas pesquisadas são signatárias do compromisso "Carta Aberta ao Brasil sobre Mudanças Climáticas". O compromisso é uma iniciativa do setor privado, com o apoio do Fórum Amazônia Sustentável e do Instituto Ethos. Seus signatários se comprometem a realizar inventários de emissóes de gases poluentes e a criar mecanismos, em suas instâncias, para orientar o desenvolvimento de uma economia de baixo carbono. Trata-se de um passo na direção da sustentabilidade, mas que necessita de outras açóes para consolidar este modelo de gestão. Destaca-se na Empresa B o "Radar da Sustentabilidade" usado para monitorar a efetividade da implementação da sustentabilidade, que indica um amadurecimento da organização nessa direção.

\section{GESTÃO DE PESSOAS}

A gestão sustentável em uma organização deve revelar seu compromisso contínuo com a melhoria da qualidade de vida dos trabalhadores, de suas famílias e da comunidade local. Competência, envolvimento e comprometimento dos colaboradores são fundamentais para o bom desempenho e produtividade das organizaçóes (Tachizawa, Ferreira, et al 2001).

A seguir, no Quadro 5, são destacados no modelo de gestão de pessoas das organizaçóes pesquisadas os aspectos relacionados a Formação e desenvolvimento de pessoas:

Com base no resultado apresentado no Quadro 5, as empresas apresentam evidências de adotarem o modelo tradicional "Treinamento e Desenvolvimento" fundamentado por uma concepção pedagógica reducionista, atendendo principalmente aos interesses econômicos e imediatistas (cursos de curta duração).

Collins e Porras (1998) apresentam a ideia de que para se perpetuar no mercado, uma empresa precisa desenvolver senso de propósito comum entre seus colaboradores e um conjunto de valores básicos para nortear comportamentos na empresa. Este é um papel fundamental que deve ser assumido pelos gestores das estruturas de Educação Corporativa nas organizaçóes empresarias comprometidas com a sustentabilidade em sua dimensão social.

A análise apresentada indica que a Empresa $\mathrm{C}$ que incorporou estratégias modernas de gestão de pessoas baseadas em modelos de Gestão por Competências, onde o ponto de partida é a clara definição do perfil de competências requeridas nas áreas de negócio da empresa.

\section{CONCLUSÓES E SUGESTÓES DE NOVAS PESQUISAS}

Os relatórios de sustentabilidade das empresas declaram que os aspectos relativos ao contexto social, político e econômico foi o direcionador para a implantação de modelos de negócio sustentável no setor da construção pesada. De uma forma em geral, as três empresas apresentam motivaçóes com origem no ambiente competitivo advindo de mudanças nos padróes de produção, da globalização da economia, exigências do contratante e de leis ambientais.

Identificam-se evidências nas três empresas estudadas da adoção de ações, políticas e diretrizes além de suas obrigaçóes legais perante o desenvolvimento sustentável. As três empresas assinaram a "Carta Aberta ao Brasil sobre Mudanças Climáticas”. Com essa evidência assumem compromisso com a Responsabilidade Social como estratégia de negócio, contribuindo com a melhoria de gestão na cadeia produtiva.

No campo do desenvolvimento de pessoas foi identificado que as empresas praticam o modelo tradicional de Treinamento e Desenvolvimento fundamentado numa concepçáo que atende principalmente aos interesses econômicos e imediatos (programas de curta duração voltados para execução de tarefas e procedimentos rotineiros).

Observa-se que as empresas têm procurado equacionar os objetivos da obtenção de lucros e da remuneraçáo de seus acionistas adotando modelos de gestão que incluem práticas de responsabilidade social ainda não integradas à estratégia do negócio, como forma de evidenciar seu compromisso com a sustentabilidade.

Todavia, este estudo destaca a necessidade de adotar-se postura crítica em relação às dinâmicas econômica, política e institucional vigentes, com a finalidade de se questionar o discurso que náo pretende modificar a estrutura social, mas que posiciona a sustentabilidade como novo elemen- 
Quadro 5: Gestão de Pessoas - Formação e Desenvolvimento de pessoas.

\begin{tabular}{|c|c|}
\hline Sujeitos da pesquisa & - Práticas Empresariais \\
\hline EMPRESA A & $\begin{array}{l}\text { - Entende que uma das principais atribuiçóes de seus líderes é educar pelo trabalho, o } \\
\text { que significa dedicar tempo e atençáo aos liderados, além de propiciar oportunidades } \\
\text { de expansão e aperfeiçoamento de conhecimentos e habilidades. } \\
\text { - As equipes são incentivadas ao exercício da crescente produtividade, criatividade e } \\
\text { reutilizaçáo dos conhecimentos gerados em suas experiências de trabalho. Anual- } \\
\text { mente a empresa realiza o Prêmio Destaque que estimula o conjunto de iniciativas } \\
\text { criativas, consolida a cultura do registro e dissemina o conhecimento. } \\
\text { - Em } 2009 \text {, os principais programas de desenvolvimento de pessoas tiveram a partici- } \\
\text { paçáo de } 65.900 \text { integrantes. } \\
\text { Os Programas Estratégicos destinam-se ao aprimoramento de competências de inte- } \\
\text { grantes estratégicos e à ampliação do conhecimento multidisciplinar. Em } 2009 \text {, os } \\
\text { principais programas tiveram a participaçáo de } 2.494 \text { Integrantes. }\end{array}$ \\
\hline EMPRESA B & $\begin{array}{l}\text { - O total de horas de treinamento em } 2009 \text { foi de } 510.648 \text { horas pata atender a } 38.028 \\
\text { empregados, o que perfaz uma média de } 13,43 \text { horas por empregado. } \\
\text { - Realizou o programa de capacitação e aprendizagem continuada das equipes que so- } \\
\text { mou } 3.692 \text { horas de treinamento técnico para } 162 \text { profissionais operacionais. Além } \\
\text { disso, o Programa de desenvolvimento de lideranças somou outras } 1.584 \text { horas } \\
\text { - Em } 2009 \text { realizou o Programa Jovens Profissionais onde } 37 \text { alunos concluíram a pós- } \\
\text {-graduaçáo em Gerenciamento de Projetos de Engenharia e Construçáo. Oitenta por } \\
\text { cento das aulas foram ministradas por profissionais da própria empresa e } 20 \% \text { por } \\
\text { professores da universidade conveniada. } \\
\text { Como suporte ao Programa, gestores são preparados para acompanhar os profissio- } \\
\text { nais em início de carreira, durante os primeiros } 15 \text { meses na companhia. }\end{array}$ \\
\hline EMPRESA C & $\begin{array}{l}\text { - No Balanced Score Card, o Índice de Treinamento é utilizado para checar se as obras } \\
\text { estáo, efetivamente, desenvolvendo o seu pessoal. } \\
\text { - A meta é um número de horas de treinamento igual ou maior do que } 3 \% \text { das horas } \\
\text { trabalhadas por obra, sendo o seu valor acumulado por superintendência, diretoria } \\
\text { e corporaçáo. O acompanhamento é feito em reuniôes mensais do Balanced Score } \\
\text { Card nas obras, diretorias e presidência. } \\
\text { - Na área de recrutamento interno, a empresa evoluiu com a implantaçáo do pro- } \\
\text { grama "Trilhas", que identifica perfis de funcionários habilitados oportunidades de } \\
\text { ascensấo nas diversas áreas e negócios do Grupo. } \\
\text { - Para as funçôes executivas, a Diretoria de Desenvolvimento de Pessoas identifica, } \\
\text { com a presidência e as diretorias, as competências essenciais para a organizaçáo, } \\
\text { independentemente da área, entendidas como vitais para que a empresa alcance os } \\
\text { resultados previstos. Sáo identificadas as metas pessoais e profissionais e é estabele- } \\
\text { cido um Plano de Desenvolvimento Individual (PDI). Ao final de cada ano, os pro- } \\
\text { fissionais são avaliados quanto ao desempenho e as metas do ano anterior previstos } \\
\text { no Balanced Score Card } \\
\text { Com base em entrevistas sáo identificados os funcionários-chave de nível operacio- } \\
\text { nal das obras (chefes, encarregados e técnicos) e, com o apoio dos superintendentes e } \\
\text { gerentes, é desenvolvido um plano de treinamentos personalizado. Sáo eleitos tutores } \\
\text { responsáveis pelo desenvolvimento } \\
\text { - Investiu na formaçáo das novas geraçóes que chegam ao mercado de trabalho. Atra- } \\
\text { vés do programa de estágio está capacitando os jovens para assumir desafios com as } \\
\text { qualificaçōes necessárias para a empresa. Os gestores, por sua vez, são treinados para } \\
\text { gerenciar e formar esses jovens. }\end{array}$ \\
\hline
\end{tabular}


to a ser facilmente integrado às práticas de gestão contemporâneas.

É unânime o discurso favorável à sustentabilidade. Nas práticas empresariais não se adotam as medidas indispensáveis para transformar os modelos de decisão, que continuam a priorizar o fator econômico em detrimento das vertentes social e ambiental. Casos relatados na literatura científica têm identificado transformaçôes superficiais e acréscimos de restriçôes legais que não são eficazes.

Existe a necessidade de avaliar as dinâmicas sociais, econômicas e do meio ambiente, estabelecer postura crítica em relaçáo a elas, negociar conflitos de interesses e, finalmente, transformar os critérios de escolhas em decisóes, para que se possam identificar genuínos esforços para a sustentabilidade empresarial. É conclusão deste estudo que no campo empresarial açóes práticas da sustentabilidade ainda se realiza na de forma incipiente e inicial. Ela se configura muito mais nos discursos e nos documentos oficiais das organizaçôes do que em seus modelos de gestáo.

Como sugestão de novas pesquisas propóe-se que pesquisas com estrutura semelhante sejam realizadas anualmente no sentido de acompanhar a evolução da tecnologia de gestáo nas empresas da construção pesada brasileira. Essas empresas, multinacionais brasileiras de importância relativa no cenário econômico nacional merecem tal atenção e acompanhamento.

\section{BIBLIOGRAFIA}

AFONSO, C. M. Sustentabilidade: caminho ou utopia? São Paulo: Annablume, 2006 .

ANTUNES M. T. P. e MARTINS E. Capital intelectual: verdades e mitos. Revista Contabilidade \& Finanças - USP, Sáo Paulo, n. 29, p. 41-54, Mai/ago 2002.

ARRUDA, L. e QUELHAS, O.L.G. Sustentabilidade: um longo processo histórico de reavaliação crítica da relação existente entre a sociedade e o meio ambiente. Boletim Técnico SENAC. Rio de Janeiro, v. 36, n.3, set./dez. 2010

BOVESPA: <http://www.bovespa.com.br>. Acesso em JANEIRO de 2013.
BRACONI, J.; O conceito de governança como contribuição à análise das transformaçôes organizacionais. Dissertação (Mestrado); Rio de Janeiro: UFRJ/COPPE, 2010.

CALIA, C. R. A difusão da produção mais limpa: o impacto do seis sigma no desempenho ambiental sob o recorte analítico de redes. Escola de Engenharia de São Carlos - Universidade de São Paulo. São Carlos, 2007. (Tese de Doutorado)

CAVALCANTI, G. F. P. Investimentos, Fontes de Financiamento e Evoluçáo do Setor de Infra-Estrutura no Brasil: 1950-1996. Ensaios Econômicos. Rio de Janeiro: FGV, EPGE, 2010

CHEIBUB, Z. e LOCKE, R. Valores ou Interesses? Reflexôes Sobre a Responsabilidade Social das Empresas. Empresa, Empresários e Globalização. Rio de Janeiro: Relume Dumará/FAPERJ, 2002.

CHESNAIS, F. A mundialização do capital. São Paulo: Xamã Editora, 1996.

COSTA, M.A.N. Fazer o bem compensa? Uma reflexão sobre a responsabilidade social empresarial. Revista Crítica de Ciências Sociais, 73, Dezembro 2005

COLLINS, J. C. e PORRAS, J. I. Feitas para durar. 6 a ed. Editora Rocco: Rio de Janeiro, 1998. 408 p.

CHESNAIS, F. A mundialização do capital. São Paulo: Xamã Editora, 1996.

DELUIZ, N. A globalização econômica e os desafios à formação profissional. Boletim Técnico do SENAC, Rio de Janeiro, v. 22, n. 2, p.15-21, Mai/ago 1996. Rio de Janeiro, v. 30, n. 2, Mai/ ago, 2004.

DELUIZ, N. e NOVICKI, V. Trabalho, Meio ambiente e Desenvolvimento sustentável: implicaçóes para uma proposta de formação crítica. Boletim Técnico do SENAC. Rio de Janeiro, v. 30, n. 2, Mai/ago, 2004.

DUPAS, G. Pobreza, desigualdad y trabajo en el capitalismo. Nueva Sociedade 215, Buenos Aires. Mai/jun 2008 
GARRIDO, P. O. Educação Corporativa Policêntrica: Aplicaçáo Transdisciplinar da Engenharia Pedagógica para a Produção da Aprendizagem Transformadora. Florianópolis, 2006 (Tese de Doutorado).

GARRIDO, P. O. Educação Corporativa Policêntrica: Aplicação Transdisciplinar da Engenharia Pedagógica para a Produção da Aprendizagem Transformadora. Florianópolis, 2006 (Tese de Doutorado).

GRI-G3. Disponível em: http://www.ethos.org. br/_Uniethos/documents/gri_g3_portugues.pdf . Acesso em: 7 jul. 12.

KRISCHKE, P. The Learning of Democracy in Latin America: Social Actors and Cultural Change, Nova York: Nova Publishers. 2001.

LAYRARGUES, P. P. Do ecodesenvolvimento ao desenvolvimento sustentável: evolução de um conceito? In Revista Proposta, no 71, p. 5-10. 1997.

LIMA, G. F. C. O discurso da sustentabilidade e suas implicações para a educação. Ambiente $\&$ Sociedade - Campinas. Vol. 6 no 2 Jul/dez 2003.

LAYRARGUES, P. P. Do ecodesenvolvimento ao desenvolvimento sustentável: evoluçáo de um conceito? In Revista Proposta, no 71, p. 5-10. 1997.

MILKOVICH, G.; BOUDREAU, J. Administração de Recursos Humanos. São Paulo: Atlas, 2000.

MEISTER, J. C. Educação corporativa: a gestão do capital intelectual através das universidades corporativas. São Paulo: Makron Books, 1999.

MILES, M.P. e COVIN, J.G. Environmental Marketing: A Source of Reputational, Competitive, and Financial Advantage. Journal of Business Ethics, v. 23, n.3, p.299-311. 2000

MILES, M. P.; MUNILLA, L.S., AND COVIN, J.G. The Constant Gardener Revisited: The Effect of Social Blackmail on the Marketing Concept, Innovation, and Entrepreneurship. Journal of Business Ethics, v. 41, n.3, p.287-295. 2002
MUNILLA, L.S. e MILES, M.P. The Corporate Social Responsibility Continuum as a Component of Stakeholder Theory. Business and Society Review, v. 110, n.4, p.371-387. 2005

PORTER, M.E. e KRAMER, M.R. Strategy and society: the link between competitive advantage and corporate social responsibility. Harvard Business Review, v. 84, n.12, p.78-92. 2006

QUELHAS O.L.G e Aride S. S. Gestão de pessoas: perspectivas da sustentabilidade humana. II Workshop Gestão Integrada: Risco e sustentabilidade. Sáo Paulo. 19 a 20 de maio de 2006. Centro Universitário Senac. (Disponível em http:// www1.sp.senac. br/hotsites/arquivos_materias/ II_workshop/Gestao_de_pessoas_perspectivas_ da_sustentabilidade_humana.pdf). Acessado em 3/10/2009.

SACHS, I. Eco desenvolvimento: crescer sem destruir. São Paulo. Vértice. 1986

SACHS, I. Rumo à ecossocioeconomia: teoria e prática do desenvolvimento. São Paulo: Cortez, 2007.

SICHE R., AGOSTINHO F., ORTEGA E., ROMEIRO A. Índices versus indicadores: precisóes conceituais na discussão da sustentabilidade de países. Ambiente \& Sociedade. Campinas v. X, n. 2. Jul/dez 2007.

TACHIZAWA, T., FERREIRA, V.C.P., FORTUNA, A.A.M. Gestão com Pessoas. Rio de Janeiro. FGV Editora, 2001.

TEIXEIRA, E. B. Educação continuada corporativa: aprendizagem e desenvolvimento humano no setor metal-mecânico. Tese de Doutorado. UFSC. Florianópolis, 2005.

VALLE, R. O conhecimento em ação: novas competências para o trabalho no contexto da reestruturação produtiva. Rio de Janeiro: Relume-Dumará, 2003.

WCED - World Commission on Environment and Development. Our Common Future. Oxford: Oxford University Press, 1987. 